\title{
Integrating the PEVs' Traffic Pattern in Parking Lots and Charging Stations in Micro Multi-Energy Systems
}

\author{
Nilufar Neyestani, Maziar Yazdani Damavandi, Radu Godina, João P. S. Catalão \\ INESC TEC and FEUP, Porto, C-MAST/UBI, Covilha, and INESC-ID/IST-UL, Lisbon, Portugal \\ ni.neyestani@gmail.com; maziar.yazdani.d@gmail.com; radugodina@gmail.com; catalao@ubi.pt
}

\begin{abstract}
In this paper, a mixed-integer linear programing (MILP) model for the traffic behavior of plug-in electric vehicles (PEVs) in a multi energy system (MES) is proposed. It is assumed that two micro-MESs are covering two traffic zones with different consumption patterns. The difference between these two micro-MESs is not only the different multi energy demand (MED) they provide but also different PEV traffic pattern that travel in these two micro-MESs. The PEVs traffic pattern and their behavior in using parking lot (PL) or charging station (CS) as their charging places is integrated in the MES operation model. The results showed that the improved strategy of the MES operator in using its components such as combined heat and power (CHP) unit and auxiliary boiler (AB) in response to extra added load of PEVs. The stochastic behavior of the PEVs is implemented in the model through various scenarios of arrival and departure.
\end{abstract}

Index Terms-- Energy hub, charging station, micro multi-energy system (MES), parking lot (PL), plug-in electric vehicle (PEV).

\section{NOMENCLATURE}

$\begin{array}{ll}\text { Acronyms } & \\ \text { AB } & \text { Auxiliary Boiler } \\ C H P & \text { Combined Heat and Power } \\ C S & \text { Charging Stations } \\ H S & \text { Heat Storage } \\ M E D & \text { Multi Energy Demand } \\ M E S & \text { Multi Energy System } \\ P E V & \text { Plug-in Electric Vehicle } \\ P L & \text { Parking Lot } \\ \text { Subscripts } & \\ e & \text { Electricity } \\ h & \text { Heat } \\ i, j & \text { The number of micro-MES } \\ t, k & \text { Time interval } \\ \omega & \text { Uncertainty Scenario } \\ \text { Superscripts } & \\ \text { Agg } & \text { PEV aggregator } \\ \text { ar } & \text { Arrived PEVs in PL or urban } \\ \text { Con } & \text { Contingency } \\ \text { del } & \text { Delegated energy } \\ \text { dep } & \text { Departed PEVs from PL or urban } \\ \text { EM } & \text { Energy Market } \\ G & \text { Gas } \\ G 2 V & \text { Grid to Vehicle } \\ \text { In, out } & \text { Input/output energy to CS or PL } \\ \text { Loss } & \text { Energy lost in PEV batteries due to traveling } \\ M E S & \text { Multi Energy System } \\ & \end{array}$

$\begin{array}{ll}M i & \text { Micro-MES } \\ P L & \text { Parking lot } \\ P V & \text { Photo-Voltaic array } \\ R M & \text { Reserve Market } \\ \text { Trans } & \text { Transformer } \\ \text { Urban } & \text { Urban traffic } \\ \text { V2G } & \text { Vehicle to Grid }\end{array}$

\section{Parameters and Variables}

$C, c$

Cd

Cost

FOR

$G, g$

$L$

$n, N$

$N S$

$Q, q$

$r$

SOC, $\mathrm{SOC}$

$\checkmark$

$\alpha$

$\beta$

$\kappa$

$\lambda$

$\pi$

$\varphi$

$\Gamma$

$\rho$

$\eta$

Capacity of PEVs or PL

Cost of battery degradation

$$
\text { Cost }
$$

Forced outage rate

Gas energy

Travel distance between zones

Number of PEVs

Number of PEVs' charging station

Heat energy

Reserve

State of charge

Average travel speed of PEVs between zones

Average travel time between zones

PEVs charging requirement

PEVs participation ratio in reserve market

Energy loss due to driving

Price

PEVs participation ratio in $\mathrm{V} 2 \mathrm{G}$ mode

Charge/Discharge rate

Probability

Efficiency

Remark I: An underlined (overlined) variable is used to represent the minimum (maximum) value of that variable.

Remark II: Capital letters denote parameters and small ones denote variables.

\section{INTRODUCTION}

Recent trends have made the plug-in electric vehicles (PEVs) inevitable components of the future systems. Therefore, it is necessary to integrate all components of the future system in an inclusive model [1].

The first impressions of electric vehicles were their charging needs in the electrical system and the load they add to the distribution grid. Later, the vehicle to grid (V2G) option has emerged to be considered as a resource in the system. Introducing massive integration of PEVs to the system through aggregator agents or PEV parking lots (PL) showed more possible impacts and benefits that the PEVs can cause in the system [2]. 
Although the PEVs' demand is only electrical, while being included in a multi-energy system (MES), the charging of the PEVs should be scheduled compatible to the prospects of the MES approach [3]. Moreover, the cross impact of PEVs and other resources cannot be neglected. The operation of the resources such as combined heat and power (CHP) units will change due to the extra load imposed to the system by PEVs [4]. The PEVs batteries as a potential storage in the system imposes certain changes in the modeling of a micro-MES [5]. However, the dynamic nature of the PEVs makes them different from the regular electric loads. The uncertain behavior of the PEV owners in using the PEVs will cause an uncertain state of charge (SOC) in the system which should be fulfilled by the MES operator.

Integrating the PEVs in multi energy systems has been the interest of some previous studies. Authors in [6] have modeled the plug-in hybrid electric vehicles (PHEVs) as an energy hub considering the driving behavior of the PHEVs. Continuing in [7], they integrated the PHEV as a component in the matrix modeling of the energy systems. In [8], the electrical load of the PHEVs is served through an energy hub and the management of their demand in the energy hub context is discussed. Charging of PHEV in a residential area in a multicarrier household is studied in [9]. These studies have added the extra load due to the electric vehicles to the total load of the multi energy system and served this load through an energy hub model. However, recent trends towards PEVs have encouraged the aggregation of PEVs for the employment of the V2G opportunity. This aspect of the PEVs has not been addressed in previous studies. In [10], the operational behavior of the PEV parking lot in one micro MES is investigated.

In this paper, the commuting of PEVs between two micro MEs is considered as the factor affecting the amount of electrical load for the multi-energy demand (MED). It is considered that two micro MESs are under central operation, but each covers areas with different usage purposes. It is assumed that both micro MESs are equipped with PEV PLs and charging stations; however, what makes them different is the behavior of the PEVs in these two different areas.

The rest of the paper is organized as follows. In Section II an overview of the problem is presented. The mathematical formulation of the problem is shown in Section III. The numerical results from are reported in Section IV. Finally, Section V concludes the paper.

\section{PROBLEM OVERVIEW}

In this study, two micro MES with different consumption patterns are considered. One of the MESs covers an area with the commercial consumption and the other one is dedicated to the area with residential usage. It is assumed that both of the MESs are equipped with CHP units, auxiliary boilers, heat storages, and photovoltaic unit and operated by a single operator. Each of the MESs serves multi energy demand regarding the consumption pattern of the area which they cover (i.e., commercial or residential).
In this study the infrastructure for the charging need of these vehicles is added to the MES model. Each of the MESs is assumed as a traffic zone for the vehicles. As the consumption pattern of these two micro-MESs are different, the behavior of the PEVs in them is accordingly different. The PEVs in the supposed model have the opportunity of charging their vehicles either in PEV PL or in urban charging stations available in the area. The PEVs PL can be available on both commercial building and residential complexes for PEVs who plan to stay for longer hours in the parking. Consequently, the PL operator will take benefit from the PEV batteries' storage in the $\mathrm{V} 2 \mathrm{G}$ mode to take part in the energy and reserve electricity market. On the other hand, for other PEVs who need a fast charging or have the estimation of a short stay in charging station, the individual charging stations in the urban area are embedded. As a result, the charging stations will only add an extra load due to the charging PEVs to the MED, while the PL other than the added load provide a storage resource for the system operator. In Fig. 1 the MES model considered for this study and its components are shown.

As seen in Fig. 1, the PL is considered as a resource in the micro MES while the CS has the characteristics of a load. Note that all of the PEVs will not be parked during the day and some of them are traveling which leads to energy consumption in their batteries. Therefore, these PEVs are also considered in the model as urban area PEVs which can also be seen in the model. The main challenge is that the charging requirements of PEVs in these two areas are different due to the different traffic pattern, parking duration, and travel distance in commercial and residential areas which will form different load pattern. On the other hand, considering the PEV PLs as storage in the energy hub model requires more accurate modeling of the PL's behavior in the charging/discharging of the PEVs. Addressing the contradictory effects of all these components in an energy hub approach is the main focus of this study.

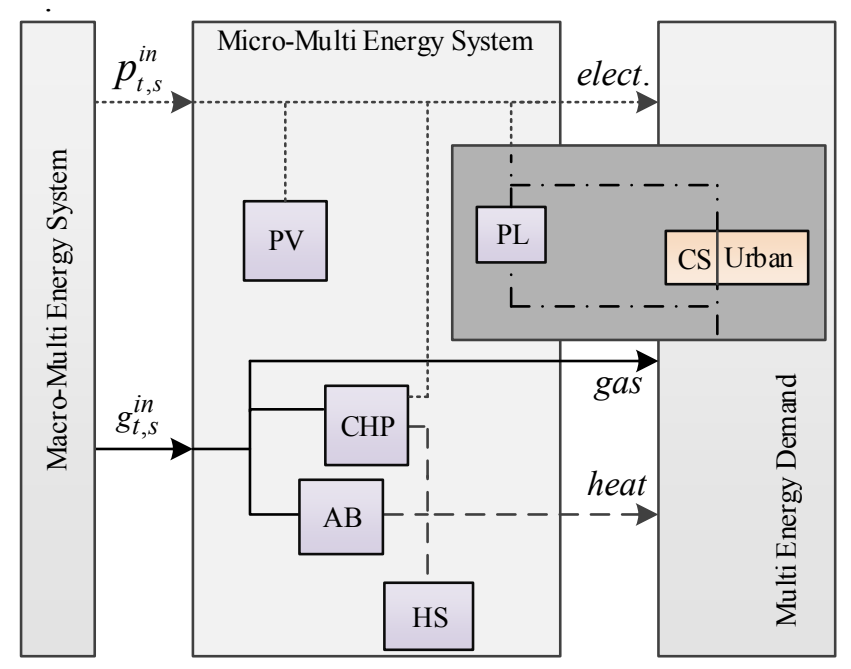

Figure 1. The integration of PEV traffic in PL and CS with MES model 
In this study, it is assumed that the PEVs commute between the residential and commercial area is based on travel purposes and is affected by the destination zone. For example, the arrival to the commercial zone is higher during working hours of the day while on the finishing hours of the day the arrival to the residential area will be higher and they stay during the night at residential zone. Moreover, it is assumed that some of the PEVs may enter these zones from other micro-MESs which are aggregated in this model and considered as environment's commute. The PEVs from the understudy MESs can also leave for the environment.

On their arrival to a zone, the PEV owners have the choice of entering PL or CS. Entering the PL is considered to be the first choice of the PEVs. Other PEVs who do not enter the PL keep driving in the area of enter the CSs. The urban area is defined for those PEVs that are not in the PL or CS. When entering the PL, the PEVs owners specify their preferences by declaring their minimum SOC requirement on their departure. This will limit the PL's transaction with the grid while discharging the PEVs batteries and also assures the PEV owners of their adequate charging status for their next travel

\section{OPERATIONAL MATHEMATICAL MODEL}

The mathematical formulation of this study is divided into two main categories: first, the MES objective and constraints and the second one the PL's.

\section{A. MES Operational model}

The MES modeled as in Fig. 1 is mathematically formulated in this subsection. As mentioned before, two micro-MESs are operated coordinately by a single operator. The objective of this operator is to minimize its total cost of supplying MED. The objective is shown in (1)

$$
\operatorname{Min}\left\{\operatorname{Cost}^{M E S}\right\}=\sum_{\omega} \rho_{\omega} \sum_{i} \sum_{t}\left(-p_{i, \omega, t}^{M i} \pi_{t}^{E M}-g_{i, \omega, t}^{M i} \pi_{t}^{G}\right)
$$

The energy balance of each micro-MES should be considered for all types of energy in micro-MES. In this study the balance for electricity, gas, and heat are shown in (2) - (4), respectively.

$$
\begin{gathered}
p_{i, \omega, t}^{M i} \eta_{e, i}^{\text {Trans }}+p_{i, \omega, t}^{C H P}-p_{i, \omega, t}^{P L, \text { in }}+p_{i, \omega, t}^{P L, o u t}+p_{i, \omega, t}^{P V}=P_{i, t}^{M E D}+p_{i, \omega, t}^{C S, \text { in }} \\
g_{i, \omega, t}^{M i}-g_{i, \omega, t}^{C H P}-g_{i, \omega, t}^{A B}=G_{i, \omega, t}^{M E D} \\
q_{i, \omega, t}^{C H P}+q_{i, \omega, t}^{A B}-q_{i, \omega, t}^{H S, \text { in }}+q_{i, \omega, t}^{H S, o u t}=Q_{i, t}^{M E D}
\end{gathered}
$$

The CHP unit's efficiency affects the output production of electricity and heat as in (5) and (6).

$$
\begin{aligned}
& p_{i, \omega, t}^{C H P}=\eta_{e, i}^{C H P} g_{i, \omega, t}^{C H P} \\
& q_{i, \omega, t}^{C H P}=\eta_{h, i}^{C H P} g_{i, \omega, t}^{C H P}
\end{aligned}
$$

However, the amount of electricity and heat production of each CHP is limited by its maximum limit. These constraints are shown in (7) and (8).

$$
0 \leq p_{i, \omega, t}^{C H P} \leq \bar{P}_{i}^{C H P}
$$

$$
0 \leq q_{i, \omega, t}^{C H P} \leq \bar{Q}_{i}^{C H P}
$$

The same circumstances are applied to the auxiliary boilers. The output heat produced from the boiler and the limitations of its production are shown in (9) and (10).

$$
\begin{aligned}
& q_{i, \omega, t}^{A B}=\eta_{h, i}^{A B} g_{i, \omega, t}^{A B} \\
& 0 \leq q_{i, \omega, t}^{A B} \leq \bar{Q}_{i}^{A B}
\end{aligned}
$$

The operational constraints for the heat storage in the MES are shown in $(11)-(15)$.

$$
\begin{gathered}
q_{i, \omega, t}^{H S}=\left(q_{i, \omega, t-1}^{H S}\right)_{t>1}+\left(0.5 \bar{Q}_{i}^{H S}\right)_{t=1} \eta_{h, i}^{H S, \text { cha }} q_{i, \omega, t}^{H S, \text { in }}-1 / \eta_{h, i}^{H S, \text { dcha }} q_{i, \omega, t}^{H S, \text { out }} \\
0 \leq q_{i, \omega, t}^{H S, \text { in }} \leq \gamma_{h, i}^{H S} \\
0 \leq q_{i, \omega, t}^{H S, \text { out }} \leq \gamma_{h, i}^{H S} \\
\underline{Q}_{h, i}^{H S} \leq q_{i, \omega, t}^{H S} \leq \bar{Q}_{h, i}^{H S} \\
q_{i, \omega, t=1}^{H S}=q_{i, \omega, t=T}^{H S}=0.5 \bar{Q}_{i}^{H S}
\end{gathered}
$$

In order to use the PV production, it should be noted that the maximum limit of its output should meet the forecasted amount as in (16).

$$
0 \leq p_{i, \omega, t}^{P V} \leq P_{i, t}^{P V, \text { Forecast }}
$$

\section{B. PEV Aggregator model}

The PEVs can be charged either in PL or in charging stations. It is assumed that the PEV aggregator manages the operation of PLs and CSs in the system. The objective of the aggregator is to maximize its profit through participating electricity energy and reserve market as well as selling energy to PEVs (17).

$$
\begin{aligned}
& \text { Profit }^{P E V-A g g}= \\
& \sum_{\omega} \rho_{\omega} \sum_{i} \sum_{t}\left[\left(p_{i, \omega, t}^{\text {out }, P L}-p_{i, \omega, t}^{\text {in,PL}}-p_{i, \omega, t}^{i n, C S}\right) \pi_{t}^{E M}\right. \\
& +r_{i, \omega, t}^{\text {out }, P L} \pi_{t}^{\mathrm{RM}}+r_{i, \omega, t}^{P L} \rho_{i, t}^{d e l} \pi_{t}^{E}-\left(p_{i, \omega, t}^{\text {out }, P L}+r_{i, \omega, t}^{P L} \rho_{i, t}^{\text {del }}\right) C d(17) \\
& -r_{i, \omega, t}^{P L} \rho_{i, t}^{\text {del }} F O R_{i}^{P L} \pi_{t}^{C o n}-r_{i, \omega, t}^{P L} \rho_{i, t}^{\text {del }} \pi_{i, t}^{V 2 G} \\
& \left.+p_{i, \omega, t}^{i n, P L} \pi_{i}^{G 2 V}-p_{i, \omega, t}^{\text {out }, P L} \pi_{i}^{V 2 G}+p_{i, \omega, t}^{i n, C S} \pi_{i}^{G 2 V}\right]
\end{aligned}
$$

where $p_{i, \omega, t}^{i n, C S}$ is the total amount of input energy to the charging stations in zone $i$.

The constraints on the PEV aggregator can be categorized into two groups. . The first group regards the constraints for the PEVs in the PL. The second one covers the constraints for the PEVs using individual charging stations or traveling inside the urban area

\section{1) PL Constraints}

It is assumed that PEVs' first choice when arriving to a zone is to stay in the PL. However, the total number of PEVs in the PL cannot exceed the total number of available stations in the PL (18). 


$$
n_{i, \omega, t}^{P L} \leq N S_{i}^{P L}
$$

The hourly number of PEVs in the PL is calculated considering the PEVs in the PL from the previous hour added to the new arrived PEVs minus the departed PEVs (19). Consequently, the total capacity of the PL is calculated by (20).

$$
\begin{gathered}
n_{i, \omega, t}^{P L}=\left.N_{i, \omega, t_{0}}^{P L}\right|_{t=1}+\left.n_{i, \omega, t-1}^{P L}\right|_{t>1}+n_{i, \omega, t}^{a r, P L}-n_{i, \omega, t}^{d e p, P L} \\
c_{i, \omega, t}^{P L}=\left.C_{i, \omega, t_{0}}^{P L}\right|_{t=1}+\left.c_{i, \omega, t-1}^{P L}\right|_{t>1}+c_{i, \omega, t}^{a r, P L}-c_{i, \omega, t}^{d e p, P L}
\end{gathered}
$$

The amount of energy that the PL can trade with the grid (input/output) is restricted by the number of its PEVs and the efficiency of the charging infrastructure (21). However, for the V2G mode of the PL, the preferences of the PEV owners on their required SOC on departure also limit the PL operator. The owners based on the estimation for their next travel submit a desirable level of SOC to the PL operator. This requirement is implemented to the model by $\phi_{i}^{P L}$ as a percentage of the total PL SOC. In other words, the PL operator aggregates the requirements of all the PEVs entering the PL and derives this number. The output of the PL should be less than the possible output due to the efficiency of the infrastructure and number of PEVs and the minimum requirement of departure SOC (22).

$$
\begin{gathered}
p_{i, \omega, t}^{i n, P L} \leq \Gamma_{i}^{P L} n_{i, \omega, t}^{P L} \\
p_{i, \omega, t}^{\text {out }, P L} \leq \min \left\{\Gamma_{i}^{P L} n_{i, \omega, t}^{P L}, \operatorname{SOc}_{i, \omega, t}^{P L} \phi_{i}^{P L}\right\}
\end{gathered}
$$

However while adding the reserve to the output of the PL, it is considered that the PEVs will be paid more on reserve call. As this situation will lead to more profit for the PEV owner, they declare another level of SOC requirement which changes the possible level of discharge for the PL operator. This amount is computed by $\kappa_{i}^{P L}$ multiplied by the total PL SOC (23).

$$
p_{i, \omega, t}^{\text {out }, P L}+r_{i, \omega, t}^{\text {out }, P L} \leq \min \left\{\Gamma_{i}^{P L} n_{i, \omega, t}^{P L}, \operatorname{soc}_{i, \omega, t}^{P L} \kappa_{i}^{P L}\right\}
$$

The PEV aggregator decides for the PL's strategy in taking part in the market based on the level of available SOC. As a result, the hourly SOC of the PL is calculated by (24) taking into account the remainder SOC of the previous hour, the SOC of arrived PEVs to the PL and the increased SOC due to the batteries charging. The SOC of departed PEVs and the possible discharging of PEVs are reduced from the total SOC. Moreover, the SOC in each hour in the PL should exceed the possible SOC derived from the total capacity of the PL multiplied by the maximum/minimum SOC of each PEV (25).

$$
\begin{gathered}
\operatorname{SOc}_{i, \omega, t}^{P L}=\left.S O C_{i, \omega, t_{0}}^{P L}\right|_{t=1}+\left.\operatorname{SOc}_{i, \omega, t-1}^{P L}\right|_{t>1}+p_{i, \omega, t}^{i n, P L} \eta_{i}^{c h a, P L} \\
-p_{i, \omega, t}^{o u t, P L} / \eta_{i}^{d c h a, P L}+\operatorname{SOc}_{i, \omega, t}^{a r, P L}-\operatorname{SOc}_{i, \omega, t}^{d e p, P L} \\
\underline{S O C}_{i}^{E V} c_{i, \omega, t}^{P L} \leq \operatorname{SOc}_{i, \omega, t}^{P L} \leq \overline{\operatorname{SOC}}_{i}^{E V} c_{i, \omega, t}^{P L}
\end{gathered}
$$

\section{2) Urban Constraints}

The rest of the PEVs in a zone that could not enter the PL will use the CSs for charging purposes or travel inside the urban area of the zone. In order to provide the needed energy for the PEVs in the zone it is necessary to know the number of the PEVs in the urban area and their required charging. The number of PEVs in the urban is calculated form the number of PEVs in the urban from the previous hour added to the number of arrived PEVs minus the departed ones as in (26). The same calculations provide the amount of capacity in the urban area (27).

$$
\begin{aligned}
& n_{i, \omega, t}^{\text {Urban }}=\left.N_{i, \omega, t_{0}}^{\text {Urban }}\right|_{t=1}+\left.n_{i, \omega, t-1}^{\text {Urban }}\right|_{t>1}+n_{i, \omega, t}^{\text {ar,Urban }}-n_{i, \omega, t}^{\text {dep,Urban }} \\
& c_{i, \omega, t}^{\text {Urban }}=\left.C_{i, \omega, t_{0}}^{\text {Urban }}\right|_{t=1}+\left.c_{i, \omega, t-1}^{\text {Urban }}\right|_{t>1}+c_{i, \omega, t}^{\text {ar,Urban }}-c_{i, \omega, t}^{\text {dep Urban }}
\end{aligned}
$$

The SOC of the PEVs in the urban area is computed from (28). It shows that the remainder of the SOC from the previous hour, the charging of the PEVs in the CSs, the arrived/departed PEVs to/from the urban and the amount of lost energy due to travel inside the zone area affects the amount of urban SOC.

$$
\begin{aligned}
\operatorname{SOC}_{i, \omega, t}^{\text {Urban }}= & \left.S O C_{i, \omega, t_{0}}^{\text {Urban }}\right|_{t=1}+\left.\operatorname{SOc}_{i, \omega, t-1}^{\text {Urban }}\right|_{t>1}+p_{i, \omega, t}^{i n, C S} \eta_{i}^{\text {cha }, C S} \\
& +\operatorname{soc}_{i, \omega, t}^{\text {ar, Urban }}-\operatorname{SOc}_{i, \omega, t}^{\text {dep Urban }}-\operatorname{Soc}_{i, \omega, t}^{\text {loss }, \text { Urban }}
\end{aligned}
$$

In addition, the SOC in the urban cannot pass the limits of its maximum or minimum capacity multiplied by the PEVs possible charging percentage (29).

$$
\underline{S O C}_{i}^{P E V} c_{i, \omega, t}^{\text {Urban }} \leq \operatorname{SOc}_{i, \omega, t}^{U r b a n} \leq \overline{\operatorname{SOC}}_{i}^{\text {PEV }} c_{i, \omega, t}^{\text {Urban }}
$$

The input power to the CSs for the PEVs charging is limited to the charging rate of the charging facilities, the number of stations, the number of PEVs in the urban area, and the available capacity of batteries in the system (30).

$$
0 \leq p_{i, \omega, t}^{i n, \mathrm{CS}} \leq \min \left\{\Gamma_{i}^{C S} N S_{i}^{C S}, \Gamma_{i}^{C S} n_{i, \omega, t}^{\text {Urban }},\left(C_{i, \omega, t}^{\text {Urban }}-\operatorname{soc}_{i, \omega, t}^{\text {Urban }}\right) \beta_{i, t}^{\text {Urban }}\right\}
$$

where $\beta_{i, t}^{\text {Urban }}$ shows the charging tendency of the aggregated PEVs in the urban area. This factor shows the probable charging trend in the CSs based on the PEV owners charging need. (31).

The energy lost due to driving inside the area is shown in

$$
\operatorname{soc}_{i, \omega, t}^{\text {loss,Urban }}=\operatorname{soc}_{i, \omega, t}^{\text {Urban }} \lambda_{i, t}^{\text {Urban }}
$$

where $\lambda_{i, t}^{\text {Urban }}$ is factor showing the percentage of fuel consumption representing the loss from the total SOC in the urban area.

The traffic pattern in this study depicts the commute of PEVs from the residential zone to the commercial one as well as their travels inside each zone. The mathematical model for this pattern is mainly based on [11]. 
The PEVs enter micro-MES \#1 from micro-MES \#2 or from other neighboring micro-MESs which is called environment in this study. Inside each zone, the division of the PEVs between PL and CS brings different level of SOC to each of these components. The interaction of SOCs due to traffic flow is shown in Fig. 2. It is assumed that the PEVs departing from one zone enter to the other zone reach there with a delay of $\alpha$ dependent on their distance and speed of travel (32). As a result, the arrival SOC to the next zone has some delay in time and also loses its quantity based on the distance traveled (33).

$$
\begin{gathered}
\alpha_{i, j}=L_{i, j} / V_{i, j} \\
k=t+\alpha_{i, j} \Rightarrow s o c_{j, i, \mathrm{k}}^{i n, \mathrm{Mi}}=\operatorname{soc}_{i, j, t}^{\text {out,Mi }}-N_{i, j, t}^{i n, \mathrm{Mi}} L_{i, j} P_{i, j}^{F u e l}
\end{gathered}
$$

Considering the traffic flow in Fig. 2 the equation defining the relation between zones will be as

$$
\begin{gathered}
\operatorname{SOc}_{i, t}^{i n, E n v}+\operatorname{SOc}_{j, i, t}^{i n, M i}=\operatorname{SOc}_{i, t}^{a r, P L}+\operatorname{SOc}_{i, t}^{\text {ar,Urban }} \\
\operatorname{SOc}_{i, t}^{d e p, P L}+\operatorname{SOc}_{i, t}^{d e p, U r b a n}=\operatorname{SOc}_{i, t}^{\text {out }, \text { Env }}+\operatorname{SOc}_{i, j, t}^{\text {out }, M i}
\end{gathered}
$$

The detailed behavior of traffic inside each MES and the division of PEVs between the PL, CS, and urban area can be found in [11]. The traffic model proposed in [11] is integrated within the operational model of the MES in the current study.

\section{NUMERICAL RESULTS}

In this paper, the effects of PEVs PL and CS on operation of MES are investigated. Two micro-MESs are considered in this study where the micro-MES \#1 covers a residential area while micro-MES \#2 is dedicated to a commercial zone. It is assumed that MES \#2 is also equipped with PV generation.

The input data for the arrival/departure of each zone is derived from [12]. Five scenarios are considered to model the stochastic behavior of the PEVs traffic pattern. The traffic flow between the zones carries the capacity shown in Fig. 3. It shows that the traffic patterns are compatible with the travel purposes of the PEVs. The peak hours of commute in microMES \#1 are early in the morning or late in the evening while for the micro-MES \#2 more commute occurs during the working hours of the day (i.e., 9-17).

The prices for energy and reserve markets are from the Spanish electricity market [13]. The PV production pattern is based on [14]. The characteristics of the micro-MES components such as the efficiencies of CHP unit, AB, and HS are obtained from [15]. It is assumed that the charging devices installed as the CS are fast charging facilities while the infrastructure installed in PLs have lower charging rate compatible with longer stay of PEVs in the PL. The assumptions for the characteristics of the charging stations are presented in Table I. The problem is modeled as a mixed integer linear programming (MILP) problem and is implemented in GAMS utilizing CPLEX12 solver.

It is assumed that the PEV aggregator and the MES operator merge as a single operator who provides energy through two
micro-MESs for the PEVs and MED. The operator can take benefit from various elements in the system to manage the best strategy of charging/discharging its PEVs as well as reducing the operational cost of the system. The results for the electricity balance are shown in Figs. 4 and 5.

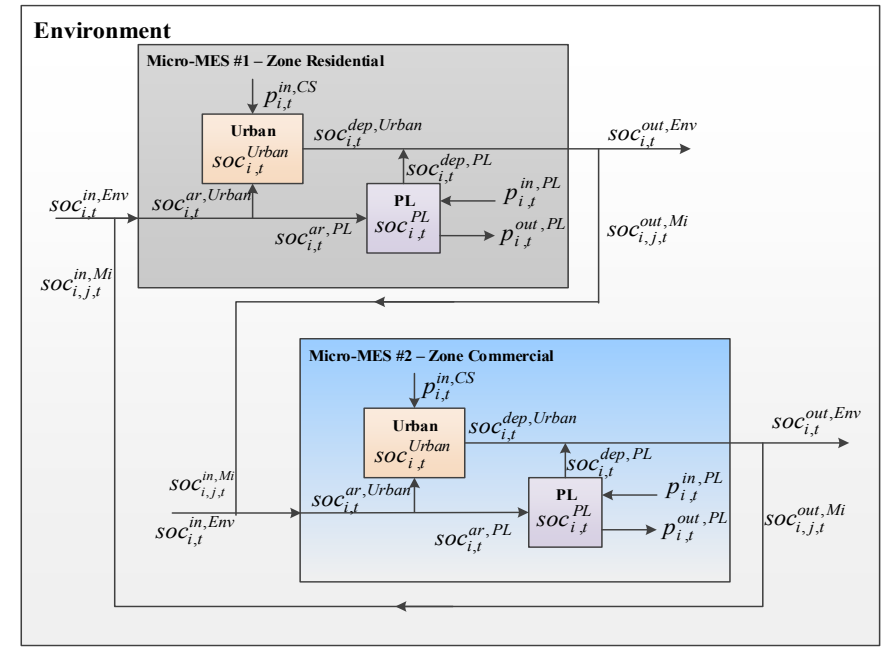

Figure 2. The integration of PEV traffic in PL and CS with MES model

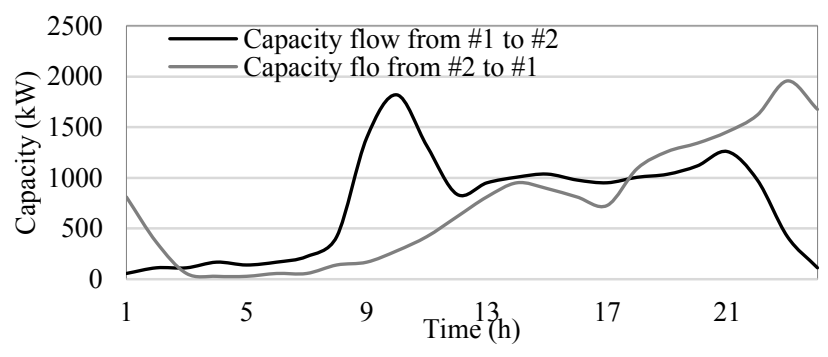

Figure 3. The traffic flow capacity between zones

TABLE I

CHARGING INFRASTRUCTURE CHARACTERISTICS

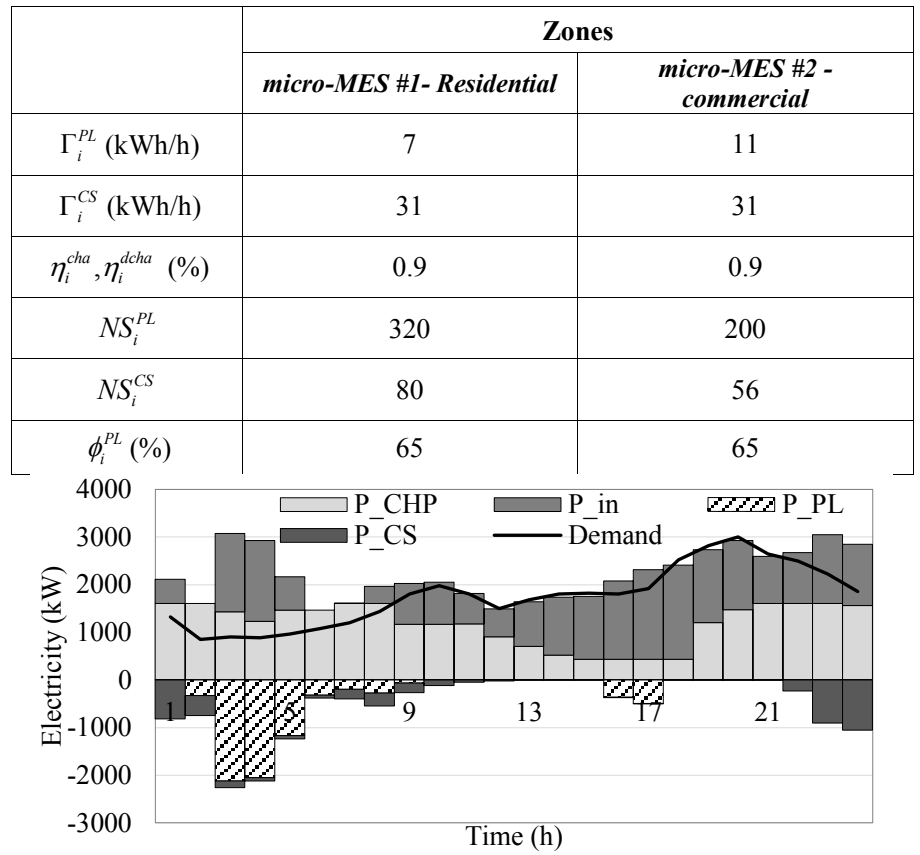

Figure 4. Electricity balance for micro-MES \#1. 


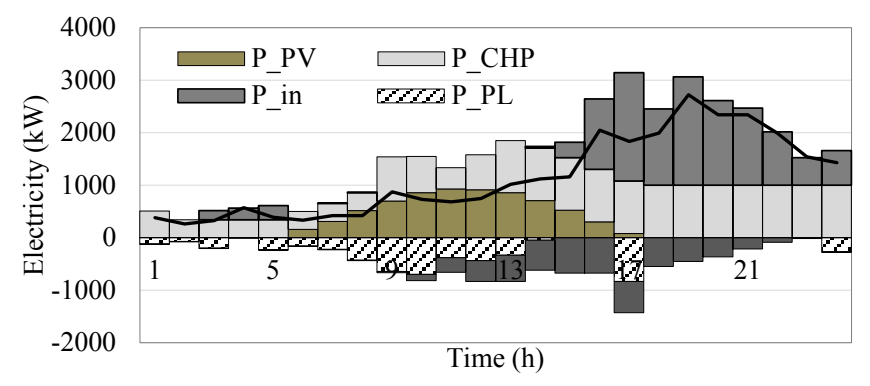

Figure 5. Electricity balance for micro-MES \#2.

The variation in the PL operation is more considerable in micro-MES \#2. As shown in Fig. 5, the production pattern of PV is similar to the peak hours of PL. Therefore, the PL's charging pattern during hours 10 to 15 is increased without increasing the input electrical energy. Moreover, the PV and the CHP unit have lower marginal cost rather than the upstream electricity market. As a result, the PL purchases the energy produced by PV and CHP unit to charge its PEVs. As the operation of CHP is increased, the heat balance for two micro-MESs are also investigated. The increased production of the CHP due to PEVs load affects the operation of auxiliary boiler. The heat demand is covered by the CHP instead of AB. These changes in the operation strategy of the MES will lead to a cost reduction of $1.5 \%$ for operating MES.

In other words, the micro-MES has a variable marginal cost for 24 hours which is due to various energy resources in the system. The dependency between the energy carriers, the uncertainty of production for the renewable resources, and the demand for a certain type of energy affects the marginal cost of each resource in the micro-MES. In this situation, the presence of PEV PL provides a degree of freedom and brings new levels of flexibility for the MES operation. The concept of the PEV PL that can act as storage in the system enables the MES operator to store the production of its resources. This cross impact of the PEV aggregation and MES resources increases the operational flexibility and enhances the market participation strategies.

\section{CONCLUSION}

In this paper an operational model is proposed to integrate the effects of the PEVs traffic pattern on the operation of PEVs PL and CS within the concept of multi energy systems. It is shown that when the PEVs are considered as the components of the MES, better operation strategies can be obtained by the system operator which leads to cost minimization. The results indicated that the purpose of the PEV travels affects the electrical load pattern which should be provided in the system. The reason is that their purpose defines the behavior of the owners on their consumption of the vehicles. As a result, imposing the purpose to the traffic pattern provides more realistic model of the PEVs' behavior. Although in this model the PL's strategy did not lead to injecting the energy saved in the batteries to the system, the profit gained by the participation in the reserve market covered the cost of supplying energy for the PEVs.
From another point of view, the PL operator can take benefit from higher level of charging which brings more income to the PL. The compatibility of resources production pattern with PL's operating hours as well as the flexible nature of the PL's operation helped the system operator to provide a better operation of the system with reduced costs.

\section{REFERENCES}

[1] M. Shulze and J. Zapata Riveros, "Impact of Electrical Vehicles on Strategic Planning of Energy Infrastructure", in Proc. International conf. Power System Technology, POWERCON, 2010.

[2] R. J. Bessa and M. A. Matos, "Economic and technical management of an aggregation agent for electric vehicles: a literature survey," Euro Trans. Elect. Power, vol. 22, pp. 334-350, 2012.

[3] M. D. Galus and G. Andersson, "Demand Management of Grid Connected Plug-In Hybrid Electric Vehicles (PHEV)," in Proc. IEEE Eneryg2030 conference, ENERGY, 2008.

[4] D. Papadaskalopoulos, G. Strbac, P. Mancarella, M. Aunedi, and V. Stanojevic, "Decentralized Participation of Flexible Demand in Electricity Markets-Part II: Application With Electric Vehicles and Heat Pump Systems", IEEE Trans. Power Syst., vol. 28, pp. 3667-3674, 2013.

[5] M. R. Haghifam, S. Pazouki, and S. Pazouki, "Renewables and Plug in Electric Vehicles Modeling on Electricity and Gas Infrastructures Scheduling in Presence of Responsive Demand," in Proc. $3^{\text {rd }}$ International Conference on electric Power and Energy Conversion Systems (EPECS), 2013.

[6] M. D. Galus and G. Andersson, "Power System Considerations of PlugIn Hybrid Electric Vehicles based on a Multi Energy Carrier Model," in Proc. IEEE Power \& Energy Society General Meeting, 2009.

[7] M. D. Galus and G. Andersson, "Integration of Plug-In Hybrid Electric Vehicles into Energy Networks," in Proc. IEEE PowerTech, Bucharest, 2009.

[8] M. Moeini-Aghtaei, A. Abbaspour, M. Fotuhi-Firuzabad, and P. Dehghanian, "Optimized Probabilistic PHEVs Demand Management in the Context of Energy Hubs," IEEE Trans. Power Syst., vol. 30, no. 2, pp.996-1006, Apr. 2015.

[9] M. Rastegar and M. Fotuhi-Firuzabad, "Optimal charge scheduling of PHEV in a multi-carrier energy home," in Proc. 14th International Conference on Environment and Electrical Engineering (EEEIC), pp. 199-203, 2014.

[10] M. Yazdani-Damavandi, M. Parsa Moghaddam, M. R. Haghifam, M. Shafie-khah, and J. P. S. Catalao, "Modeling Operational Behavior of Plug-in Electric Vehicles' Parking Lot in Multienergy Systems," IEEE Trans. Smart Grid, DOI: 10.1109/TSG.2015.2404892.

[11] N. Neyestani, M. Yazdani-Damavandi, M. Shafie-khah, and J. P. S. Catalao, "Modeling the PEV traffic pattern in an urban environment with parking lots and charging stations," in Proc. IEEE conference PowerTech Eindhoven, 2015.

[12] G. Pasaoglu, D. Fiorello, L. Zani, A. Martino, A. Zubaryeva, and C. Thiel, "Projections for Electric Vehicle Load Profiles in Europe Based on Travel Survey Data," European Comm. Rep. EUR 25993 EN, 2013, [Online]. Available: https://setis.ec.europa.eu/publications/jrc-setisreports.

[13] Red Eléctrica de España, "Maximum average hourly power demand and daily energy," [Online]. Available: ttp://www.ree.es

[14] Spanish Power System Archive, 2010 [Online]. Available: http://www. esios.ree.es.

[15] N. Neyestani, M. Yazdani-Damavandi, M. Shafie-khah, G. Chicco, and J. P. S. Catalao, "Stochastic Modeling of Multienergy Carriers Dependencies in Smart Local Networks With Distributed Energy Resources,” IEEE Trans. Smart Grid, vol. 6, no. 4, July 2015. 